\title{
La democratización del cuidado en la enfermería Argentina. Aspectos sociohistóricos develados con perspectiva de género.
}

The democratic care in Argentine nursing: Historical and social aspects unveiled by gender perspective.

\section{Democratização o cuidado em enfermagem Argentina. Aspectos sciohistóricos revelou com perspectiva de gênero.}

\author{
Javier Alejandro Mendizábal \\ Licenciado en Enfermería, Maestrando en Bioética. Docente e investigador. Universidad Nacional de Mar del Plata. \\ Cómo citar este artículo en edición digital: Mendizábal, J.A. (2018). La democratización del cuidado en la enfermería Argenti- \\ na. Aspectos sociohistóricos develados con perspectiva de género. Cultura de los Cuidados (Edición digital), 22(50). Recuperado \\ de http://dx.doi.org/10.14198/cuid.2018.50.06 \\ Correspondencia: Funes No 3350. Nivel +4. CP. 7600. Mar del Plata. Buenos Aires. Argentina. \\ Correo electrónico: javiermendizabalroces@hotmail.com \\ Recibido: 28/04/2017; Aceptado: 15/10/2017
}

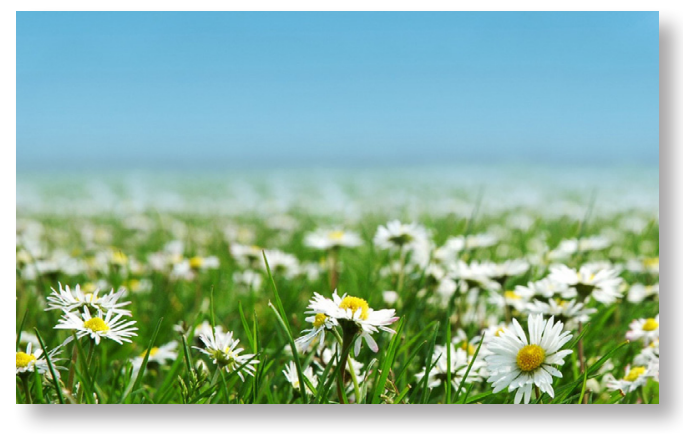

\section{ABSTRACT}

Introduction: the consolidation of medical; religious; patriarchal and of the healthcare consumption market hegemony in the world of nursing, has emphasized professional subordination and colonized healthcare in order to collaborate in sustaining the status quo. It seems essential to open a discussion about this problem in the context of an established democracy since the 1980s in Argentina. To achieve this, it would be necessary to highlight some advances and setbacks in women's citizenship and in nursing care that have structured the process of professionalization from a critical discussion of radical democracy and full citizenship with a gender perspective. Objective: to identify the grammar of interaction, the subjectivities across it and the different forms of Coloniality present in the profession through the gender matrix to account for the lines of care that attempt or promote sovereignty with plurality. Method: historiographic study of theoretical analysis. Results: different historical periods in Argentinean nursing have evidenced the possibility of expanding or restricting the citizenship of the profession in a very unequal way and subject to the civil and political participation of the public. The consolidation of democracy since the 80 s has enabled disciplinary development, with law of professional practice - and the recognition of autonomy - a historical and political turning point with scarce symbolic capitalization. The practice continues to be influenced by historical oppressive burdens entailing a form of care which becomes undemocratic. Conclusions: radical democracy, as the scales of justice appear as conceptual frameworks of vital political discussion within the profession to identify 
democratic care and ensure full citizenship of professionals and who should receive democratic care.

Key words: Gender health politics, nursery, Argentinian history, democratic care.

\section{RESUMEN}

Introducción: la consolidación de la hegemonía médica, religiosa, patriarcal y del mercado de consumo en salud ha impreso en la enfermería mundial subordinación profesional y ha colonizado al cuidado para colaborar en sostener el status quo. Parece imprescindible proponer una discusión acerca de esta problemática en el contexto de democracia consolidada a partir de los años 80 en Argentina. Para ello será necesario, destacar algunos avances y retrocesos en la ciudadanía de las mujeres y enfermería que han vertebrado el proceso de profesionalización con perspectiva de género y desde la discusión crítica de democracia radical y ciudadanía plena. Objetivo: identificar la gramática de interacción, las subjetividades que la atraviesan y las diferentes formas de colonialidad presentes en la profesión a través de la matriz de género para dar cuenta de las líneas de cuidado que atentan o promueven la soberanía con pluralidad. Método: estudio historiográfico de análisis teórico. Resultados: distintos períodos históricos en la enfermería Argentina han evidenciado la posibilidad de ampliar o restringir la ciudadanía de la profesión de forma muy desigual y sujeta a la participación civil y política del colectivo en la arena pública. La consolidación de la democracia desde los años 80 ha posibilitado el desarrollo disciplinar siendo la ley de ejercicio profesional $-y$ el reconocimiento de la autonomía- un punto de inflexión histórico político y social de escasa capitalización simbólica. La práctica continúa influenciada por las cargas opresoras históricas entramando cuidados que devienen antidemocráticos. Conclusiones: la democracia radical, como las escalas de justicia aparecen como marcos conceptuales de vital discusión política dentro de la profesión para identificar un cuidado democrático y garantizar la ciudadanía plena de los profesionales y quienes deben recibir cuidados democráticos.

Palabras clave: Género, políticas en salud, enfermería, historia Argentina, cuidado democrático.

\section{RESUMO}

Introdução: a consolidação da hegemonia médica, religiosa, patriarcal e do mercado de consumo em saúde tem impresso na enfermagem mundial subordinación profissional e tem colonizado ao cuidado para colaborar em sustentar o status quo. Parece imprescindível propor uma discussão a respeito desta problemática no contexto de democracia consolidada a partir dos anos 80 em Argentina. Para isso será necessário, destacar alguns avanços e retrocessos na cidadania das mulheres e enfermagem que têm vertebrado o processo de profissionalização com perspectiva de gênero e desde a discussão crítica de democracia radical e cidadania plena. Objetivo: identificar a gramática de interação, as subjetividades que a atravessam e as diferentes formas de colonialidad presentes na profissão através da matriz de gênero para dar conta das linhas de cuidado que atentam ou promovem a soberania com pluralidade. Método: estudo historiográfico de análise teórica. Resultados: diferentes períodos históricos na enfermagem Argentina têm evidenciado a possibilidade de ampliar ou restringir a cidadania da profissão de forma muito desigual e sujeita à participação civil e política do coletivo na opinião pública. A consolidação da democracia desde os anos 80 
tem possibilitado o desenvolvimento disciplinar sendo a lei de exercício profissional -e o reconhecimento da autonomia- um ponto de inflexão histórico político e social de escassa capitalización simbólica. A prática continua a ser influenciada por encargos históricos opressivos que envolvem cuidados que se tornam antidemocráticos. Conclusões: a democracia radical, como as escalas de justiça aparecem como marcos conceituais de vital discussão política dentro da profissão para identificar um cuidado democrático e garantir a cidadania plena dos profissionais e de quem devem receber cuidados democráticos.

Palavras Chave: Gênero, políticas em saúde, enfermagem, história Argentina, cuidado democrático.

\section{INTRODUCCIÓN}

La posibilidad de reflexionar acerca de la influencia de la globalización en políticas en enfermería a cargo de líderes profesionales y de qué forma operan y se imprimen los intereses del mercado y la corporación médica como representantes de la hegemonía capitalista y patriarcal en salud han motivado interrogantes acerca de las dificultades en la participación política de enfermería.

La consolidación de la hegemonía médica, religiosa, patriarcal y del mercado de consumo en salud ha impreso en la enfermería mundial subordinación profesional y ha colonizado al cuidado para colaborar en sostener el status quo. Parece imprescindible proponer una discusión acerca de esta problemática en el contexto de democracia consolidada a partir de los años 80 en Argentina. Para ello será necesario, en primer lugar, destacar algunos avances y retrocesos en la ciudadanía de las mujeres y enfermería que han vertebrado el proceso de profesionalización. En segundo lugar, discutir la situación actual paradójica entre la sanción de la ley 24.004, que regula el ejercicio profesional en los años 90, un Estado democrático que intenta consolidarse, oportunidades políticas cooptadas por las mujeres y la imposibilidad de fracturar la subordinación de enfermería en la percepción de la profesión y su práctica. Por último se propone una perspectiva, en sintonía con la idea de democracia radical y ciudadanía plena, que invita a ofender la subordinación y pasividad política en enfermería, provocar discusiones que promuevan críticas a la estructuración invisibilizada y dinamicen otra enfermería y otros cuidados.

Se intentará analizar entonces, por un lado, la crisis identitaria en enfermería ancladas en restricciones ciudadanas históricas por diversas hegemonías y la potenciabilidad de engenerar a través de la propuesta de democracia radical de Mouffe (1993). Por otro se buscará comprender el efecto de estas restricciones a partir del cuidado profesional y la crítica a las divisiones dicotómicas masculino/femenino advirtiendo además ciertos riesgos que exponen algunas perspectivas feministas. Por último se presenta la idea de cuidado democrático como estrategia de poder político profesional, emancipatorio de la persona cuidada y estrategia de política pública alternativa distributiva para la transformación de la ciudadanía plena según Fraser (2006).

La noción de "engenerar" a la enfermería Argentina surge como "posibilidad de interrogar algún aspecto de la realidad social, y/o institucional, desde el andamiaje epistemológico de «la teoría feminista»" (Lugones, 2008, p. 86) para proponer pensar otra enfermería en el sentido que Vargas (2011) y Escobar (2012) reclaman "otros mundos posibles" inspirados en el Foro Social Mundial. Esta búsqueda no 


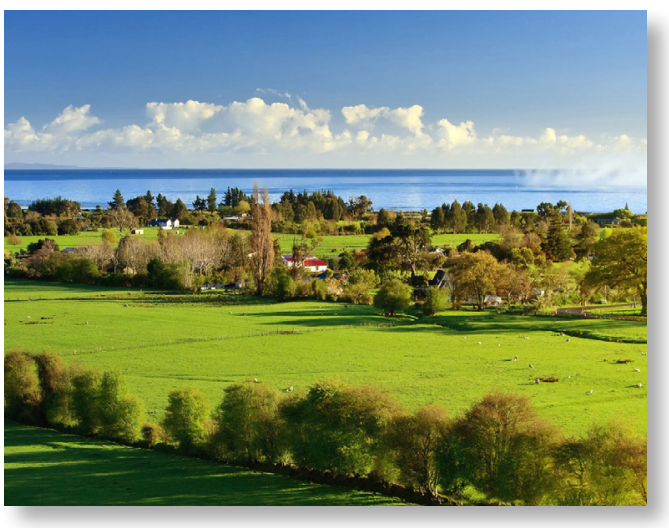

es arbitraria. El último autor destaca la noción de posmodernismo opositor de Boaventura de Sousa Santos "la tarea a la que nos enfrentamos no es la búsqueda de soluciones modernas a los problemas modernos, sino el imaginar soluciones realmente novedosas con base en la práctica de los actores sociales de mayor proyección epistemológica y social." (Escobar, 2012, p.13)

Se considera improbable comprender la situación de la enfermería actual sin previamente considerar las cuatro vías opresivas que pueden ubicarse localmente y/o en la región latinoamericana y/o a nivel global. Esta propuesta rechaza universalizar la opresión en la profesión, pero invita a percibirla con diversas intensidades, similares orígenes en marcas identitarias insatisfactorias de una profesión feminizada y de notoria restricción ciudadana. Estas podrían reconocerse como la hegemonía de la academia cientificista, biologicista, de ética utilitarista con control social (Sacchetti y Rovere, 2011) y liberalista (Dietz 2001; Pateman 1996); la hegemonía capitalista de codicia ilimitada en acumulación económica, a través de la mercantilización de la salud con permanente medicalización (Illich, 1974) e intervención biopolítica (Foucault, 1977); la hegemonía religiosa cristiana bajo la autoridad del cuidado abnegado y caritativo, de los ma- les divinos, que inicia su salida provocada por la academia con resistencia vigente (Morrone, 2013; Capurro 2013) y la hegemonía patriarcal, que desde la perspectiva que aquí se intenta argumentar, se retroalimenta de las tres anteriores: el esencialismo biológico -discutido desde la inclusión/exclusión que plantea Mouffe (1993)- , la división sexual del trabajo y la doble moral cristiana desde la identidad reproductiva/ productiva y pública/privada (Paterman, 1996).

\section{MÉTODO}

Se parte de un estudio historiográfico con la intención de elaborar una explicación científica de las sociedades en su transcurso temporal con perspectiva de género y la demostración palpable de la influencia del pasado (Fhilo, 2016) sobre la actualidad de la profesión en Argentina. La revisión teórica y documental surge de la formación de postgrado en la maestría en género, políticas públicas y sociedades en FLACSO, como de la participación del proyecto de investigación: Análisis desde una perspectiva de género y desde la genealogía histórica de la profesionalización: la percepción sobre las CyMAT en la enfermería que ejerce en instituciones de la salud pública. Se trabajaron principalmente fuentes secundarias dedicadas a la historia de la enfermería y género en Argentina; además de fuentes primarias orales de enfermeras que laboraron en asistencia y docencia después de la segunda mitad del siglo XX.

\section{RESULTADOS}

\section{¿La enfermería moderna sin ciudadanía?}

El nacimiento de la enfermería moderna finalizando el siglo XIX con Nightingale en Inglaterra (Attewell, 1998) y Grierson en Argentina trae el apogeo de las mencionadas hege- 
monías. La visión feminista liberal de Grierson que pensó a la enfermería mixta fue controlada bajo decreto en el año 1912 (Wainerman y Binstock, 1992; Sacchetti y Rovere, 2011; Morrone, 2016). La feminización correspondía a la ideología esencialista "mujer hay una sola" criticada por Mouffe (1993).

La naturalización de los roles por la división sexual del trabajo a partir del avance del capitalismo en actividades productivas para los hombres y reproductivas para las mujeres se fue identificando con la moral religiosa y la idea de liberalismo patriarcal. Pateman identifica esto último a través de teóricos como Locke y su "respuesta definitiva a la tesis patriarcal según la cual el poder paterno y el político son uno y el mismo, debido a la dependencia natural de los hijos respecto de sus padres." (Paterman, 1996, p.7). En defensa de las libertades individuales propuestas a partir del utilitarismo se dividió el ámbito privado donde se iniciará la lucha por la igualdad de las mujeres en materia de derechos civiles pero separadas del mundo público y político. Según esta línea, se pensó a la enfermería hospitalaria-militar bajo órdenes de rango que se adoptan en el mundo de los hombres y la comunitaria para el control social-sanitario que avalaba ingresar a la vida privada (Sacchetti y Rovere, 2011). Esta especialidad invade un espacio impedido al panóptico religioso y de la salud pública para garantizar la transformación del miasma moral que opera bajo una doble moral que Vargas (2011) destaca entre colonialidad del poder y del saber. El cuidado se coloniza desestimando los saberes reproductivos e imponiendo en la formación bases biológicas centradas en la enfermedad patógena. Cabe destacar, que para sostener la lógica utilitarista, que encuentra la utilidad en avalar a la mujer trabajadora en el mundo público en un liberalismo desigual es necesario reconocer la asociación entre moral religiosa y la clases altas como la sociedad de Beneficencia en Argentina como fuerzas de control profesional (Morrone, 2016).

Si "Para entonces, la sujeción de las mujeres era total; no tenían una posición legal o civil independiente y habían quedado reducidas a la condición de propiedades" (Pateman, 1996, p. 8) con derechos civiles desiguales, políticos inexistentes y sociales colonizados la profesión se transitó sumisa y el cuidado naturalizado a través de la idea de función reproductora sin valor productivo en el mercado. La puja capitalista en salud provocó que el cuidado del otro en la salud y la enfermedad se minimice y vire a cuidar los intereses de la hegemonía médica anhelando una igualdad peligrosa para enfermería.

\section{No hay una sola mujer: Del coraje de politi- zar la profesión.}

La lucha feminista por los derechos políticos, especialmente al sufragio, fue posible en Argentina en un momento de ganancia en los conceptos de libertad e igualdad. En el nacimiento del Estado de Bienestar y a partir del año 1945 se conquistó un nuevo escenario para la ciudadanía. El Plan Analítico de Salud presentado por Ramón Carillo en el año 1946, como primer Ministro de Salud, reivindicó derechos sociales en relación a la salud de toda la población. Surge así un ejemplo de la articulación de derechos políticos y sociales. Se crea la Escuela de Enfermería de Eva Perón (EEEP). (Morrone, 2013; 2016). El valor participativo de ciudadanía política fue apropiado por las enfermeras de las EEEP. Según Bareiro "está estrechamente vinculado a los de democracia y de conformación de una comunidad política" (1997, p.2). El poder de consolidar este derecho debía evidenciarse en su ejercicio 
a través de una matriz ideológica distinta. Se propiciaba un escenario para iniciar la participación política en el autogobierno de la profesión y recuperar el objeto de estudio. Morrone $(2013$; 2016) realiza una comparación con la Escuela de Enfermería del Ministerio de Salud que no logra desprenderse de la Sociedad de Beneficencia y la impronta de la religión católica donde las imágenes las muestran en actos de rodillas frente a un crucifijo en el Ministerio de Salud. En cambio las enfermeras de la EEEP se muestran en los actos conduciendo vehículos, exhibiendo perros entrenados para rescate y sin presencia masculina/médica. Más allá del proceso de desperonización en 1955 que logra la disolución de la escuela y la persecución política partidaria, social y civil de las graduadas y su posterior invisibilización histórica (Morrone, 2014) evidencian el poder de la profesión frente a las hegemonías, como también, las consecuencias de una idea y ejercicio de ciudadanía igualitaria. Esta experiencia marca la diferencia de falsos opuestos entre democracia representativa y participativa propuesta por Bareiro y Torres (2010). La militancia partidaria de las enfermeras de la EEEP promovió la participación democrática gestando la posibilidad "de organizarse de tal modo que pueda ejercer una influencia directa en las decisiones públicas" (Bareiro y Torres, 2010, p.13). La muerte de Eva Perón y el golpe de Estado les imposibilitaron acceder a la representación democrática que permitiera defender las ganancias en ciudadanía para esas mujeres y enfermeras mientras otras enfermeras preferían no cuestionar, conservar o imponer la única esencia femenina posible: con vocación de fe, cuidadoras por naturaleza materna y auxiliares de la medicina. Esta situación subordinó más aún a la profesión, reduciendo los planes de estudio y promoviendo la formación de au- xiliares de enfermería. Las enfermeras que se alinearon asimétricamente con la hegemonía patriarcal médica se transformaron en representantes antidemocráticas, otras permanecieron en la abnegación vocacional padeciendo las condiciones y medio ambiente de trabajo (CyMAT) desfavorables y otras buscaron una salida a partir de una nueva lucha política: el reconocimiento legal como profesión autónoma que les permita percibir igualdad ciudadana frente a la sociedad y el equipo de salud -especialmente el médico- además de diferenciarse recuperando el objeto de estudio.

\section{Ampliando ciudadanía y la ley de ejercicio profesional. Negando derechos.}

Los años 80 y 90 en Argentina muestran un esfuerzo por sostener la fragilidad democrática en el Estado. Bareiro y Riquelme (1998) resaltan la voluntad de vivir una democracia plural evitando las fuerzas políticas imponerse como única ideología, concentrar poder y permanecer. En este nuevo escenario se avienen derechos políticos civiles y sociales negados en la última dictadura pero ante la amenaza neoliberal de dejar libre a las reglas del mercado derechos ganados y otros por discutirse. Así como se vieron amenazados derechos sociales fueron permeables otros que en sintonía al liberalismo -no patriarcal como insiste Pateman (1996) en este caso- fue posible la ley de cuotas que posibilitó incrementar la representación femenina y específicamente para enfermería la sanción de la ley nacional de ejercicio profesional 24.004 en 1991.

Esta conquista con efecto en la ciudadanía política, social y civil desde lo profesional "convierte paradójicamente a la ley en amenaza” (Morrone, 2016, p.182) El poder que otorga la ley, en el reconocimiento de la autonomía profesional, no se ha materializado como 
soberanía en el ejercicio desde lo colectivo. Por contario, la subordinación ha promovido negar la vigencia de la ley, incumplir obligaciones y garantizar derechos para el personal de enfermería y a quienes reciben cuidado. En consecuencia, se garantiza la defensa de los intereses institucionales y del saber médico sosteniendo la incapacidad de orientar el objeto de estudio hacia el cuidado profesional. Se deviene una nueva crisis identitaria.

Gastaldo, Linardi y Peter (2006) critican la sumisión de la enfermería cuestionando por un lado la escaza participación política y por otro la invalidez ética del cuidado a partir de la imposibilidad del cuidado de sí y de la defensa del paciente. Las autoras destacan la dificultad para reconocer o estimar el poder de la profesión y las consecuencias de ignorarlo. En Argentina desde los noventa significa desestimar deberes éticos e irresponsabilidad legal. De esta manera resulta complejo pensar las capacidades colectivas de interpelar por mejoras en las CyMAT y en otros aspectos imprescindibles para el empoderamiento profesional y cuidados de calidad como es la formación continua exigida en todos los códigos deontológicos ${ }^{1}$ y la ley de ejercicio nacional.

La formación superior en enfermería a través de universidades y la formación de grado han intentado recuperar el objeto de estudio y promover en la sociedad a la enfermería autónoma para lograr reconocimiento profesional. En este intento de sanación identitaria se logran reconocer tres vertientes a partir de la propuesta de Dietz (2001). Una de ellas puede reconocerse en el cuidado productivo, otra puede encontrarse en sostener el cuidado maternalista profesionalizado y la última en la producción del cuidado a través de la salud colectiva.

El primero puede verse en la promoción del Consejo Internacional de Enfermería (2015) sobre la Enfermería Basada en Evidencia y la Enfermería de Práctica Avanzada que disputan en el terreno biomédico, bajo la idea de igualdad, en el "liberalismo la ciudadanía llega a ser no tanto una actividad colectiva y política como una actividad individual y económica: el derecho a perseguir los propios intereses sin impedimentos en el mercado" (Dietz, 2001, p.6). En la mercantilización de la salud la enfermería puede disputar, desde el cuidado, la producción a partir de la competencia individual. Esta actitud requiere de eficiencia productiva que desestime el contexto socio económico y cultural en el cuidado para primar los resultados biológicos y medicalizados y con uso de tecnologías duras. Lo individual inhibe la discusión política colectiva, opera en defensa de la igualdad frente al equipo de salud pero envistiendo la identidad medica. De alguna manera, la búsqueda de igualdad representa la hegemonía opresora y la deshumanización ${ }^{2}$ del cuidado.

La producción del cuidado desarrollada por Merhy (2006) sustentada en la corriente de salud colectiva aparece similar a las críticas del feminismo Marxista contra el liberalismo según Dietz (2001). Merhy no hace distinciones entre médicos o enfermeras al hablar de la producción del cuidado integrando la división sexual del trabajo y lo entiende como un pro-

\footnotetext{
${ }^{1}$ Aquí se hace referencia a los códigos deontológicos de enfermería regionales (del MERCOSUR y FEPPEN) e internacional (Consejo Internacional de Enfermería)

${ }^{2}$ Se utiliza el término por su familiaridad pero adhiriendo a las críticas de Onocko Campos (2004) Humano demasiado humano: un abordaje del malestar en las instituciones hospitalaria. En Salud Colectiva, Spinelli (org). Buenos Aires, Argentina: Lugar. pp.103-120.
} 
ceso complejo único por su contexto en el encuentro humanizado entre cuidador y cuidado que denomina micropolítica de trabajo vivo y donde priman los saberes de ambos como tecnologías blandas y donde las tecnologías blandas duras -el saber clínico- y las duras de alta complejidad mecánica-eléctrica más invasivas se desestiman ya que se busca promover la salud y resolver la enfermedad. Esta noción destaca la función social del cuidado y se opone a servir a los intereses capitalistas del mercado. Dietz (2001) reconoce la importancia de la lucha de clases e igualdad económica con justicia social pero considera que esta lucha disminuye la construcción ciudadana desde la política y se pregunta “'hay algo más en la política feminista que la lucha revolucionario contra el estado?" (p. 9)

Desde la enfermería, parece en primer lugar, muy difícil revolucionar el cuidado. Transformar desde la corriente de salud colectiva de forma individual, inserto en una institución estructurada con actores/agentes sin motivación política y sin discusión ideológica, se convierte en un padecimiento entre propuesta utópicas, confusión entre saberes y práctica y/o frustración laboral. Resulta indispensable una participación política que sea permeable a los derechos individuales para una ciudadanía con pluralidad.

El cuidado maternalista profesionalizado aparece en oposición a la búsqueda liberal de igualdad demarcando el mundo de las diferencias, "se identificarían con una concepción de la conciencia política femenina asentada en las virtudes de la esfera privada de las mujeres, primordialmente en la maternidad" (Dietz, 2001, p.9). A diferencia de la producción del cuidado o el cuidado productivo se propone el cuidado reproductivo profesional. Se destacan los saberes maternales naturales de las mujeres en el ámbito privado para insertarlos en la vida pública. Esta concepción escencialista es indisociable de la idea vocacional que sobrepone las CyMAT desfavorables que mundialmente denuncia la enfermería en resignación ante el sacrificio y el amor en los cuidados. Esta impronta será sostenida por universidades Católicas y movimientos religiosos con influencia institucional. De esta manera la noción de democracia como la soberanía popular con pluralidad de Mouffe (Bareiro y Torres, 2010) es cercenada por la imposición maternalista identificada con la beneficencia en detrimento de la autonomía profesional y en la capacidad de cuidar ya que el saber le pertenece sólo a la enfermera/madre/mujer.

La ética del cuidado (a partir de Gilligan y criticada por Mouffe 1995; Dietz 2001) desestimará la justicia social buscada por el feminismo marxista y la distributiva con igualdad de oportunidades de Rawls. Los obstáculos continúan emanando de la misma enfermería que con intención de homogenización en las asociaciones profesionales y académicas dificultan un debate político plural.

\section{CONCLUSIÓNES: FUTUROS ¿POSIBLES?}

La necesidad de pensar un cuidado democrático se imprime en el respeto por las igualdades y las diferencias y cómo de alguna manera será necesario articularlas. "Así pues, la democracia nos ofrece una identidad que ni el liberalismo, con su propensión a contemplar al ciudadano como individuo portador de derechos, ni el maternalismo, con la atención que presta a la maternidad, nos proporcionan." (Dietz, 2001, p.12). Mouffé (1995) propone rechazar los esencialismos que reivindican la maternidad como diferencia natural y el liberalismo que busca la igualdad vitalizando lo bi-genérico como categorías de disputa políti- 
ca. Lo precario y contingente de las relaciones sociales requiere una multiplicidad de saberes de cuidado imposible de encorsetar un estereotipo profesional. En este sentido estructurar una enfermería y la práctica del cuidado parece atentar contra la democracia que se pretende proteger.

La propuesta parece demandar participación política como ejercicio de la soberanía popular, no sólo en la práctica del cuidado del otro con perspectiva plural social, cívica y política sino además el cuidado de sí a través de la representación en espacios de enfermería e interdisciplinarios.

"comprometidas con un proyecto político cuya aspiración sea luchar contra las formas de subordinación que existen en muchas relaciones sociales, y no sólo contra aquellas vinculadas al género, una interpretación que nos permite entender cómo es construido el sujeto a través de diferentes discursos y posiciones de sujeto es ciertamente más adecuada que una interpretación que reduzca nuestra identidad a una posición singular ya sea de clase, raza o género." (Mouffe, 1995, p. 11)

La identidad en enfermería, a través de la recuperación del cuidado democrático, podrá debatirse respetando intersubjetividades, reconociendo las relaciones de poder como positivos emancipadores o negativos opresores. La subordinación profesional incompatible con los derechos en salud y una dialéctica permanente entre el respeto a la diversidad identitaria de cada sujeto y aquella que construye la profesión.

Parece interesante la propuesta de Fraser (2006) para repensar la profesión y el ejercicio siguiendo la teoría crítica del reconocimiento de diferencias que sea compatible con políticas de igualdad social. De esta manera las políticas de reconocimiento respetan las diferencias culturales en doble vía: por ejemplo reconociendo el derecho a la objeción de conciencia profesional y en el derecho a un cuidado plural.

Además las políticas de redistribución ${ }^{3}$ permiten un diálogo equitativo frente a las tensiones de acceso a la salud y el cuidado integrando nuevas perspectivas a problemáticas graves de la salud pública como el aborto, el acceso a la salud, la mortalidad materna, o las lesiones por causas externas en Argentina.

\section{BIBLIOGRAFÍA}

- Attewell, A. (1998). Florence Nightingale: Perspectivas. Revista trimestral de educación comparada, 28(1), 57-71.

- Bareiro, L. (1997). Construcción femenina de ciudadanía. $1^{\circ}$ ed. Venezuela: Nueva Sociedad.

- Bareiro, L., Torres, I. (2010). Gobernabilidad democrática, género y derechos de las mujeres en Latino América y Caribe. Paraguay: Centro de documentación y Estudios.

- Bareiro, L., Riquelme J. (1998). ¿Cuál es el debate de la democracia? Cuaderno del Centro Latinoamericano de Capacitación y Desarrollo de los Gobiernos Locales. 26,15-22.

- Capurro, L. (2013). Hay otra historia. Un hospital, una Universidad y una incipiente asociación de enfermería. En B. Morrone (Comp.) Al servicio de las ideas: la enfermería en los procesos populares de liberación en Iberoamérica. (p. 49-121) 2 ed. Mar del Plata: Suarez.

- Consejo Internacional de Enfermería (CIE) (2015). Las enfermeras, una fuerza para el cambio: eficaces en cuidados, eficientes en costos. Ginebra, Suiza: Autoedición.

- Dietz, M. (2001). Ciudadanía con cara feminista. El problema con el pensamiento maternal. En: M. Lamas (Comp) Ciudadanía y feminismo. Mexico: Metis -productos culturales S.A.

\footnotetext{
${ }^{3}$ Fraser recupera la noción de distribución y la articula en redistribuir a partir de las esferas materiales y sociales.
} 


\section{Cultura de las Cuidados}

- Escobar, A. (2012). Más allá del Tercer Mundo: globalización y diferencia. Bogotá: Instituto Colombiano de Antropología e Historia.

- Filho, AJA. (2016). A pesquisa histórica: teoria, metodologia e historiografia. Here. Historia da enfermagem; $7(2): 381-2$.

- Foucault, M. (1977). Historia de la medicalización. Educación médica y salud, 11(1), 32-58.

- Fraser, N., \& Honneth, A. (2006) ¿Redistribución o reconocimiento? Madrid: Morata.

- Gastaldo, D., Lunardi, V., Peter, E. (2006). ¿Es ética la sumisión de las enfermeras? Una reflexión acerca de la anorexia de poder. Enfermería clínica, 16 (5), 268274. Disponible en https://dialnet.unirioja.es/servlet/ articulo? codigo $=2107778$

- Illich, I. (1974). Medical Nemesis. London: Calder and Boyars.

- Lugones, M. (2008). Colonialidad y género. Tabula Rasa. 1 (9), 73-101.

- Merhy, E. (2006). Salud: Cartografía del trabajo vivo. Buenos Aires: Lugar Editorial.

- Morrone, B. (2013). Profesionales militantes y políticas: las graduadas de la escuela de enfermería de la fundación Eva Perón (1948-1955). En B. Morrone (Comp.) Al servicio de las ideas: la enfermería en los procesos populares de liberación en Iberoamérica (pp. 129-169) 2ºd.
Mar del Plata: Suarez.

- Morrone, B. (2016). Soltando amarras: claves para comprender la historia pendiente de la enfermería argentina. 5 ta ed. Mar del Plata: Suarez.

- Mouffe, C. (1995). Feminismo, ciudadanía y política democrática radical. En M. Lamas (Comp.) Ciudadanía y feminismo (pp. 1-14) Méjico: Unifem. Recuperado de: http://mujeresdelsur.org/sitio/images/descargas/chantal_mouffe\%5B1\%5D.pdf\%20ciudadania\%20y\%20feminismo.pdf

- Sacchetti, L., Rovere, M. (2011). Surgimiento de la enfermería moderna: Mitos victorianos, tecnologías de poder $y$ estrategias de género. $1^{\mathrm{a}}$ ed. Rosario: El Agora.

- Pateman, C. (1996). Críticas feministas a la dicotomía público/privado. Barcelona: Paidós.

- Vargas, V., (2011). América Latina en el siglo XXI: la diversidad como paradigma emancipatorio. Conferencia en la Biblioteca del Instituto de Estudios Latinoamericanos de la Universidad de Estocolmo, Estocolmo, Suecia. Recuperado de http://ahbx.eu/ahbx/?p=2001

- Wainerman, C., y Binstock, G. (1992). El nacimiento de una ocupación femenina: La enfermería en Buenos Aires. Desarrollo Económico, 32 (126), 271-284. Recuperado de http://catalinawainerman.com.ar/pdf/El-nacimiento-de-una-ocupaci-femenina-La-nferme.pdf

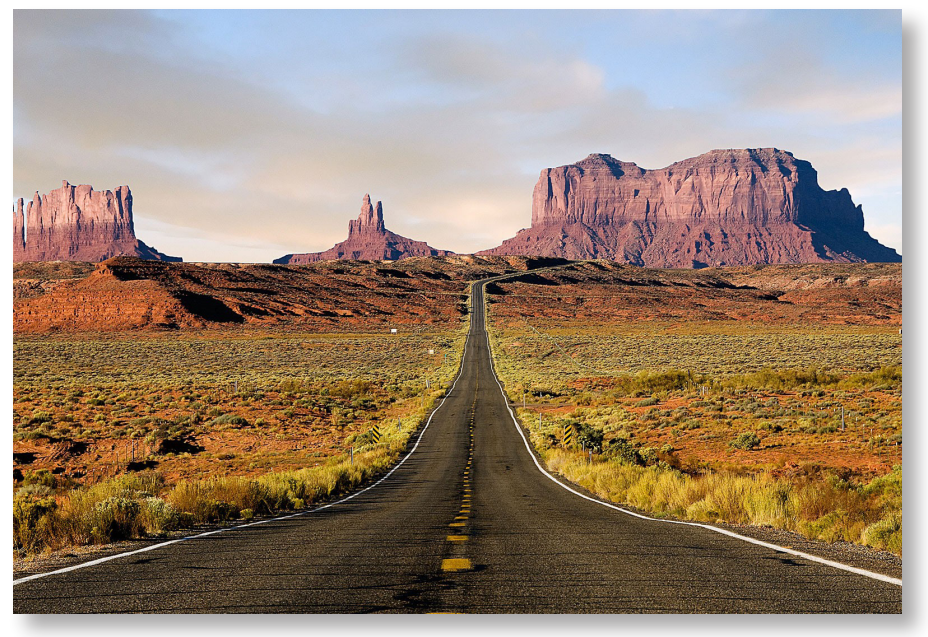

